\title{
High-efficient determination of niclosamide in tablet based on multiple-walled carbon nanotubes/cyclodextrins composite modified glassy carbon electrode
}

\author{
Cuiling Wang ${ }^{1,2,3, *}$, Jiateng Zhong ${ }^{2}$, Gaiping Zhang ${ }^{1, *}$, Jianhe $H u^{3, *}$ \\ ${ }^{1}$ College of Animal Science and Veterinary Medicine, Henan Agricultural University, Zhengzhou \\ 450000, China \\ ${ }^{2}$ School of Basic Medical Science, Xinxinag Medical University, Xinxiang 450003, China \\ ${ }^{3}$ College of Animal Science and Veterinary Medicine, Henan Institute of Science and Technology, \\ Xinxiang 453003, China \\ *E-mail: Wangcl0229@163.com ; Jianhehu@126.com ; zhanggaiping2003@163.com
}

doi: $10.20964 / 2021.02 .23$

Received: 14 October 2020 / Accepted: 5 December 2020 / Published: 31 December 2020

\begin{abstract}
Niclosamide (NA) is a commonly used teniacide against cestodes infecting humans. In order to realize the high-efficient determination of NA, an electrochemical sensor was fabricated with the multiplewalled carbon nanotubes/cyclodextrins composite modified glassy carbon electrode (MWCNT/CD/GCE), which was applied to analyze the NA residual. Multiple-walled carbon nanotubes (MWCNT) showed a one-dimensional nanorod structure with high electrical conductivity and large specific surface area, and cyclodextrins (CD) with good molecular recognition performance could promote the uniform dispersion of MWCNT. The fabricated MWCNT/CD/GCE sensor gave full play to their respective advantages of MWCNT and $\mathrm{CD}$, which effectively improved the determination performance of NA. Under the optimal conditions, the fabricated MWCNT/CD/GCE sensor exhibited good determination performance of NA with a low detection limit of $19.5 \mathrm{nM}$ in a great linear NA concentration of $0.06-0.8 \mu \mathrm{M}$ and 1-15 $\mu \mathrm{M}$. Moreover, the MWCNT/CD/GCE sensor showed a good practicability for the determination of NA in tablet.
\end{abstract}

Keywords: Multiple-walled carbon nanotubes; Cyclodextrins; Niclosamide determination; Electrochemical sensor; Tablet

\section{$\underline{\text { FULL TEXT }}$}

(C) 2021 The Authors. Published by ESG (www.electrochemsci.org). This article is an open access article distributed under the terms and conditions of the Creative Commons Attribution license (http://creativecommons.org/licenses/by/4.0/). 